\title{
Investigation of Galactomannan/deacetylated Chitosan Nanocomposite Films and their Anti- bacterial Properties
}

Wanying Liu

Nanjing Forestry University

Zhe Ling

Nanjing Forestry University

Caoxing Huang

Nanjing Forestry University

Chenhuan Lai

Nanjing Forestry University

Qiang Yong ( $\nabla$ swhx@njfu.com.cn )

Nanjing Forestry University

\section{Research Article}

Keywords: galactomannan, deacetylated chitosan, nanocomposite film, antibacterial property

Posted Date: February 19th, 2021

DOl: https://doi.org/10.21203/rs.3.rs-218235/v1

License: (c) (i) This work is licensed under a Creative Commons Attribution 4.0 International License. Read Full License 


\section{Abstract}

A little packaging is a wonderful thing, a lot of packaging is a nightmare, particularly when landfills around the world threaten to engulf our living space. The topic of edible packaging is still of interest to the food industry and other organization funding research to solve packaging dilemmas. In this research, galactomannan (GM) was used as raw material and deacetylated chitosan (DE-ChN) was used as strengthening modifier to prepare GM based packaging films. The chemical structure of the composite film was analyzed with SEM and FTIR. The properties influence for films of different DE-ChN content were studied. The obtained GM/DE-ChN nanocomposite films showed superior hydrophobicity and high tensile strength. The nanocomposite films against Escherichia coli, Bacillus subtilis, Staphylococcus aureus and Streptococcus pneumoniae showed great antibacterial properties. Moreover, the GM and GM/DE-ChN nanocomposite film showed no toxicity to RAW264.7 macrophage cells. The final obtained GM/DE-ChN packaging film provides a foundation for the potentials for futural plastic packaging alternatives.

\section{Introduction}

Consumers' growing awareness of healthy lifestyles has prompted people to explore new technologies that can extend the shelf life of food without using preservatives. Due to its ability to improve the quality of foods, edible films and coatings are specially considered in food preservation. Today, traditional biobased polymers from biomass have been gradually applied to food packaging films and coatings materials, and the commercialization of biopolymer film and coating has become more profound (Galus and Kadzińska 2015). Natural substrates such as polysaccharides, proteins, and lipids can be used to make edible films and coatings (Gutiérrez et al. 2015). The changes in the mechanical properties and barrier properties of the main components in the biopolymer matrix have aroused people's interest in composite structures, which enables people to explore the complementary advantages of each component and minimize its shortcomings (Lee et al. 2004).

Polysaccharides such as starch, cellulose, chitosan, pullulan and Tara gum are some of the most normally used materials for producing edible films (Wu et al. 2012; Xiao et al. 2012). Galactomannan (GM) is a representative polysaccharide, GM derived from the Sesbania cannabina seed endosperm is a natural renewable polysaccharide, which can effectively reduce the use of non-renewable petroleum resources when preparing food packaging materials. At the same time, it can be used as a safe edible film to reduce consumers' concerns about the safety of food packaging. However, the single GM film has poor mechanical properties, and is brittle, which is not conducive to its application. It is often necessary to add hydroxyl groups and polyols to improve the tensile strength, flexibility, etc. of the film, avoiding the surface breakage of the film after preparation, and making the film surface smooth (Li et al. 2019). Glycerin, polyvinyl alcohol and polysaccharides containing hydroxyl groups are commonly used plasticizers. These plasticizers are similar to polysaccharides because of their molecular structure. Hydrogen bonding will occur between shared hydroxyl groups, but different plasticizer molecules differences in structure, size, C, O element content and spatial configuration lead to different film-forming properties (Antoniou et al. 2014). 
As a deacetylation product of natural polysaccharide chitin, deacetylated chitosan (DE-ChN) has many excellent physical and chemical properties, such as biocompatibility, biodegradability, non-toxicity, multireactivity, low irritation, broad-spectrum antibacterial properties, etc. (Verlee et al. 2017; Ye et al. 2018). There have been a large number of literatures reported that chitosan has broad-spectrum antibacterial properties, and has a good inhibitory effect on a variety of bacteria, fungi, and even some viruses. Park et al. found that the fresh-keeping time of strawberries covered with chitosan film was prolonged and the water loss was significantly reduced (Park et al. 2005). In addition, chitosan also has broad application prospects in the biomedical industry.

The antibacterial properties of DE-ChN are closely related to its degree of deacetylation, molecular weight, solvent and $\mathrm{pH}$ of the system. The surface of $\mathrm{DE}-\mathrm{ChN}$ is rich in amino groups, which is the key to the antibacterial properties of DE-ChN. At present, a large number of scholars have studied the influencing factors of chitosan's antibacterial properties (Sudarshan et al. 1992; Kong et al. 2010). Researchers have found that the source (Chien et al. 2016), deacetylation degree, molecular mass, and concentration of chitosan have a great influence on the antibacterial effect (No et al. 2002; Zheng and Zhu 2003). At the same time, the $\mathrm{pH}$, water content, external factors such as solvents also have a significant impact on the antibacterial ability of chitosan.

In this paper, different amount of DE-ChN were added into GM to prepare GM/DE-ChN nanocomposite films. The effects of different concentration of DE-ChN on the nanocomposite film's mechanical properties, hydrophobicity, thermal stability and four common antibacterial properties were investigated. The final prepared GM based functional food packaging film provides a foundation for the potentials for futural plastic packaging alternatives. The prepared functional food packaging film based on GM can be used as a plastic packaging alternative.

\section{Experimental}

\section{Materials}

Sesbania cannabina seed endosperm was purchased from Lianyungang city (Jiangsu Province, China). Chitin with a degree of deacetylation of $6.9 \%$ was purified from crab shells (Eriocheir sinensis) as described in the Liu et al work (Liu et al. 2016). All other chemicals were of analytical grade. E. coli (CGMCC 1.8723), B. subtilis (CGMCC 1.3358), S. aureus (CGMCC 1.2465) and S. pneumoniae (CGMCC 1.8722) were purchased from China General Microbiological Culture Collection Center (CGMCC) for the antibacterial test.

\section{Preparation of GM}

In order to separate GM, the Sesbania cannabina seed endosperm was swelled in distilled water for 24 hours, and then mechanically crushed using a juicer. The resulting slurry was stirred at $50^{\circ} \mathrm{C}$ for $24 \mathrm{~h}$, and then centrifuged to separate the suspended solids. From the supernatant GM solution, GM was 
precipitated with $95 \%(\mathrm{v} / \mathrm{v})$ ethanol (The volume ratio of GM and ethanol was 1:3) and washed with additional ethanol of $95 \%(\mathrm{v} / \mathrm{v})$. The precipitated and washed GM was then freeze-dried to yield a powder after the ethanol was evaporated under a fume hood. Finally, the average molecular weight (Mw) of GM was calculated by gel permeation chromatography to be 430,000 Daltons (GPC, Agilent Technologies, Santa Clara, CA, USA), the extracted GM sample consisted of $91.43 \pm 0.36 \%$ galactomannan was determined by high performance liquid chromatography (HPLC, ICS 3000, Dionex, USA). The molar ratio of mannose to galactose was determined to be 2.10. These results indicated that the extracted GM was a biomacromolecular with higher purity and high molecular weight, and thus is an ideal matrix for making various materials.

\section{Preparation of DE-ChN}

Partially deacetylated chitin was prepared as described in a previous report (Fan et al. 2010). Purified chitin was suspended in a (30\%wt) $\mathrm{NaOH}$ solution and heated at $90^{\circ} \mathrm{C}$ for $4 \mathrm{~h}$, partially deacetylated chitin with degree of deacetylation of about $25 \%$ was prepared successfully, after deacetylation, the sample was collected and washed with distilled water until the supernatant reached a neutral $\mathrm{pH}$. Then the sample was freeze-dried.

To prepare DE-ChN, the sample after freeze-dried was dispersed in distilled water at a concentration of $0.4 \%(\mathrm{w} / \mathrm{v})$, and the $\mathrm{pH}$ was adjusted to 3 using acetic acid under constant stirring; then, the suspension was homogenized at 10,000 rpm for $30 \mathrm{~s}$ by a homogenizer (T25, IKA, Germany) and the sonication procedure was conducted at $500 \mathrm{~W}$ for $5 \mathrm{~min}$ (an interval of $3 \mathrm{~s}$ ) by an ultra-sonicator (VCX500, USA) and repeated for 5 times; finally the dispersion was centrifuged, and the supernatant was collected as the DE$\mathrm{ChN}$. For further use, DE-ChN dispersions with $0.5 \%(\mathrm{w} / \mathrm{v})$ were prepared by dilution or concentration using rotary evaporation.

\section{Preparation of GM/DE-ChN nanocomposite films}

To prepare GM/DE-ChN nanocomposite films, the GM solution $(10 \mathrm{~g} / \mathrm{L})$ was first obtained at $50^{\circ} \mathrm{C}$ with 3 h constant stirring. The GM/DE-ChN nanocomposite films were prepared by ultrasonic dispersion and solution casting. A series of DE-ChN with mass fractions of $20 \%, 40 \%$ and $60 \%$ (according to the dry weight of GM) were gradually added to the GM solution under stirring. After ultrasonic defoaming treatment, the above mixture was poured into a polytetrafluoroethylene mold diameter of $9 \mathrm{~cm}$ and dried in an oven at $40^{\circ} \mathrm{C}$ and the nanocomposites films were obtained. All films were stored at $25^{\circ} \mathrm{C}$ and $50 \%$ relative humidity $(\mathrm{RH})$ for at least $48 \mathrm{~h}$ before measurement. The composite films were named $\mathrm{GM}$, $\mathrm{GM} / 20 \% \mathrm{DE}-\mathrm{ChN}, \mathrm{GM} / 40 \% \mathrm{DE}-\mathrm{ChN}, \mathrm{GM} / 60 \% \mathrm{DE}-\mathrm{ChN}$ and DE-ChN according to the amount of DE-ChN (0-60\%), respectively.

\section{Characterization of GM/DE-ChN nanocomposite films}


The micro-morphology of nanocomposite films was observed by scanning electron microscopy (SEM) using a Quanta 200 (FEl, American) microscope. The cross section of the films was obtained by applying liquid nitrogen freeze-cracking composite films. To prepare the sample for imaging, the film was pasted onto a row of staples with the cross section facing upwards. The fixed film was then coated with a $20 \mathrm{~nm}$ gold layer before recording SEM images.

The light transmittance spectra of nanocomposite films were detected in the range of $200-900 \mathrm{~nm}$ using a UV- vis spectrophotometer (Ultrospec 2100, Amersham Bioscience).

The FT-IR spectra of the original GM film, DE-ChN film and GM/DE-ChN nanocomposite film samples were scanned from 400 to $4000 \mathrm{~cm}^{-1}$ in a Nicolet Antaris FT-IR apparatus under dry air at $30^{\circ} \mathrm{C}$.

The mechanical properties (tensile strength and elongation) of GM/DE-ChN nanocomposite films were measured with a TRAPPEZIUM $X$ type tester (Shimadzu Corporation, Japan). Each tested film was cut into $10 \times 50 \mathrm{~mm}$ specimens. The tensile strength at break of GM/DE-ChN nanocomposite film was measured with a sensor equipped with a load of $500 \mathrm{~N}$. The span length and testing speed were $30 \mathrm{~mm}$ and $1 \mathrm{~mm} / \mathrm{min}$, respectively. Five specimens of each film were tested and the mean values of the results were calculated.

Thermogravimetric analysis (TGA) of GM/DE-ChN nanocomposite films was carried out with a TGA/209F1 (Libra, German) instrument with a sample weight of approximately 5-15 mg and a heating rate of $10^{\circ} \mathrm{C} \mathrm{min}^{-1}$ from $30^{\circ} \mathrm{C}$ to $800^{\circ} \mathrm{C}$ under flowing nitrogen.

The hydrophobicity of the prepared films was evaluated by recording the water contact angle using an Attension Theta contact angle system apparatus (Biolin Scientific, Sweden). During the measurement, a 4 $\mu \mathrm{L}$ water droplet was dropped on the surface of nanocomposite film and the contact angle was calculated from the average of three parallel samples.

\section{Cytotoxicity evaluation of GM/DE-ChN nanocomposite films}

Cytotoxicity evaluation of GM/DE-ChN nanocomposite films were carried out in vitro using RAW 264.6 cells (Mouse monocyte macrophages). First, both a GM solution, DE-ChN solution and an GM/DE-ChN solution (concentrations of $25-400 \mu \mathrm{g} / \mathrm{mL}$ ) were added to a macrophage medium and cultured with the cells at $37^{\circ} \mathrm{C}$ for $24 \mathrm{~h}$ in 96 -well flat-bottom plate $\left(2 \times 10^{4}\right.$ cells/well). Then, each solution $(100 \mu \mathrm{L})$ was added to a 10-fold dilution CCK-8 reagent at room temperature in the dark for $1 \mathrm{~h}$. The absorbance of the macrophages cultured in the GM and GM/DE-ChN solutions was determined at $450 \mathrm{~nm}$.

\section{Antibacterial performance}

To investigate the germicidal ability of the GM/DE-ChN nanocomposites films, a shake flask method was used to test against B. subtilis, E. coli, S. aureus and S. pneumoniae. After cultivation in liquid lysogeny 
broth (LB) medium (containing $10 \mathrm{~g} / \mathrm{L}$ peptone, $5 \mathrm{~g} / \mathrm{L}$ yeast extract, and $10 \mathrm{~g} / \mathrm{L}$ sodium chloride) for $12 \mathrm{~h}$ at $37^{\circ} \mathrm{C}$, the microorganisms were diluted with the LB liquid culture medium to obtain a bacterial suspension with approximately $1.0 \times 10^{6} \mathrm{CFU} / \mathrm{mL}$ concentration. According to Xu et al work (Xu et al. 2019), $0.01 \mathrm{~g}$ composites film was immersed in $10 \mathrm{~mL}$ of bacterial suspension adjusted pH 5.5. The solution was then cultured in a shaker stirring at $150 \mathrm{rpm}$ and at $37^{\circ} \mathrm{C}$ for $6 \mathrm{~h}$. Then, a $100 \mu \mathrm{L} \mathrm{of} 7$-fold serial dilutions was pipetted into agar plates. The mixture was incubated in incubator at $37^{\circ} \mathrm{C}$ for $12 \mathrm{~h}$ and the number of bacteria was obtained using the colony forming count method.

\section{Statistical analysis}

Statistical analysis was performed using a commercial SPSS program (SPSS 20.00, SPSS INC., Chicago, Illinois, USA). The data were expressed as mean \pm standard deviation (SD) and $p<0.05$ was taken as the minimal level of significance.

\section{Results And Discussion}

\section{Morphology and UV absorption of GM/DE-ChN nanocomposite films}

DE-ChN has been widely reported in the preparation of composite film, which endows the composite film excellent chemical and physical properties. Light transmittance is an auxiliary means to evaluate the compatibility of polymers. If the compatibility between DE-ChN and GM molecules in the GM/DE-ChN nanocomposite film is poor, then light reflection or scattering will occur at the phase interface between them, the light transmittance of the film is reduced. The film prepared by mechanically mixing had a smooth surface and higher transparency due to its high level of uniformity (Gennadios et al. 1998).

Digital images of the composite film showed the transparency of the film as can be seen from Fig. 1. The original GM film was slight matt, and the light transmittance of the GM film compounded with DE-ChN increased from $73 \%$ (original GM film) to $86 \%$ (GM/60\% DE-ChN film). Both films had no UV absorption. Figure. 2a' e' displayed the SEM images of the cross-section of GM/DE-ChN nanocomposite films with different content of DE-ChN addition. All the cross-section SEM images of GM/DE-ChN nanocomposite film showed a multilayer structure, just like the physical structure of natural mother pearl shellfish, so the composite film had good physical and chemical properties (Wang et al. 2017).

\section{FT-IR analysis of GM/DE-ChN nanocomposite films}

To investigate the effect of DE-ChN on the structure of the GM films, the chemical bonds in the original GM film, DE-ChN film and the GM/DE-ChN nanocomposite film were surveyed using ATR-FTIR. When a $H$ atom was connected to $\mathrm{O}, \mathrm{F}$ and other atoms with a small radius and strong electronegativity, the electron cloud moved and exposed the $\mathrm{H}$ atom nucleus, which was easily electrostatically attracted to other atoms with lone pairs of electrons, forming a strong dipolar effect, this was the hydrogen bond, which would 
affect the infrared spectrum. From Figure. 3, it can be seen that the FTIR spectra range of 3310-3350 $\mathrm{cm}^{-1}$ indicated the- $\mathrm{OH}$ and the $-\mathrm{NH}$ stretching vibration. The $-\mathrm{CH}$ stretching vibration was attributed to the range of $2800-3000 \mathrm{~cm}^{-1}$. The typical amino bond of chitosan wavenumber appeared in the range of $1620-1720 \mathrm{~cm}^{-1}$ and $1520-1580 \mathrm{~cm}^{-1}\left(1500 \mathrm{~cm}^{-1}, 1655 \mathrm{~cm}^{-1}\right.$ and1630 $\left.\mathrm{cm}^{-1}\right)$ due to the amine $\nabla$ and ه (Martins et al. 2012; Li et al. 2013; Darbasi et al. 2017). The ATR-FTIR spectra contained intense bands at $1647 \mathrm{~cm}^{-1}(\mathrm{C}=0), 1016 \mathrm{~cm}^{-1}$ (C-O-C and C-OH on the pyran ring) (William Kemp 2002). The $1380 \mathrm{~cm}^{-}$

${ }^{1}$ was the absorption peak of $-\mathrm{CH}_{3}$ symmetric deformation vibration and $-\mathrm{CH}$ bending vibration (Lawrie et al. 2007), which proved that chitosan was successfully compounded on GM (Jóźwiak et al. 2017).

\section{Mechanical properties of GM/DE-ChN nanocomposite films}

The mechanical properties of the original GM film, DE-ChN film and GM/DE-ChN nanocomposite film materials were shown in Table 1. Compared with the original GM film, the tensile strength values of GM/DE-ChN nanocomposite films improved significantly. This was because chitosan has higher mechanical properties than that of GM due to its linear characteristics. The interaction mechanism of DE$\mathrm{ChN}$ and GM in nanocomposite films as can be seen from Figure.4. The addition of polysaccharide enhanced the hydrogen bonding force between GM molecules, thereby increasing the tensile strength of the GM/DE-ChN nanocomposite film (Mollah et al. 2016). According to the data in Table 1, when the addition amount of DE-ChN was $60 \%$, the maximum tensile strength of GM/DE-ChN nanocomposite film was $107 \mathrm{MPa}$, which was $343 \%$ higher than the original GM film. Similar results were reported by Pinotti et al. (Pinotti et al. 2007) who indicated the reduction in methylcellulose film flexibility with increasing chitosan concentration. Khan et al. (Khan et al. 2012) reported that chitosan incorporation (5\%-36\% wt) in methylcellulose-based films significantly improved the tensile strength of films with the reduction of viscoelasticity. The $50 \%$ chitosan containing starch-based films was considered as the optimum because the films had good strength (47 MPa). Moreover, the appearance of the films was quite transparent. As the content of chitosan increased, the hydrogen bonding force between polysaccharide molecules increased, and the tensile strength of the corresponding film also increased.

Table 1

Mechanical properties of GM/DE-ChN nanocomposite films

\begin{tabular}{|llll|}
\hline Sample & Tensile strength $(\mathrm{MPa})$ & Elongation at break $(\%)$ & Young's module (GPa) \\
\hline GM & $31.2 \pm 5.2$ & $7.5 \pm 3.9$ & $1.8 \pm 0.6$ \\
\hline DE-ChN & $110.1 \pm 6.0$ & $4.1 \pm 0.3$ & $4.1 \pm 0.4$ \\
\hline GM/20\%DE-ChN & $80.6 \pm 4.1$ & $4.6 \pm 0.7$ & $3.2 \pm 0.4$ \\
\hline GM/40\%DE-ChN & $103.0 \pm 2.9$ & $6.6 \pm 1.4$ & $4.1 \pm 0.4$ \\
\hline GM/60\%DE-ChN & $107.1 \pm 9.8$ & $3.3 \pm 0.9$ & $4.0 \pm 0.5$ \\
\hline
\end{tabular}




\section{TGA and DTG analysis of GM/DE-ChN nanocomposite films}

The thermal stability of the GM/DE-ChN nanocomposite films with different DE-ChN addition amounts were shown in Fig. 5. The weight loss of the composite films was divided into the following three stages which can be observed from Fig. $5 \mathrm{~A}$. The first weight loss started from $40^{\circ} \mathrm{C}$ to $150^{\circ} \mathrm{C}$. This part was mainly the physical removal of water in the GM and DE-ChN composite film. The next step started at about $250^{\circ} \mathrm{C}$, and the $\mathrm{GM}$ began to decompose at high temperature (Pang et al. 2015). The ash content of GM film, GM/20\% DE-ChN film, GM/40\% DE-ChN film, GM/60\% DE-ChN film and DE-ChN film were $16.3 \%, 20.5 \%, 22.9 \%, 27.1 \%$ and $20.1 \%$, respectively. The maximum degradation temperature was 298.3 ${ }^{\circ} \mathrm{C}, 293.8^{\circ} \mathrm{C}, 288.4{ }^{\circ} \mathrm{C}, 286.6^{\circ} \mathrm{C}$ and $268.7^{\circ} \mathrm{C}$, respectively. It could be seen from Fig. 4 that the change trend of the residual mass fraction was GM/60\% DE-ChN > GM/40\% DE-ChN > GM/20\% DE-ChN > DE-ChN $>$ GM. From the derivative thermogravimetric analysis curve (DTG) of the composite films, it could be seen that the original GM film, the original DE-ChN film and the GM/DE-ChN naocomposite film had different endothermic peaks in the DTG curve. The endothermic peak of the GM composite film with different addition amounts of $\mathrm{DE}-\mathrm{ChN}$ had shifted. This characteristic due to the different degradation temperature of the material. The degradation temperature of the original $\mathrm{GM}$ film was about $300^{\circ} \mathrm{C}$, while the DE-ChN/GM composite film had a second endothermic peak at $400{ }^{\circ} \mathrm{C}$ (Yao et al. 2006a). For the original DE-ChN film, the maximum degradation temperature started at about $400{ }^{\circ} \mathrm{C}$, so the DE-ChN/GM composite film had a third peak, but the original GM film did not contain DE-ChN without this peak. The results showed that the GM composite film added with $\mathrm{DE}-\mathrm{ChN}$ still maintained the thermal stability of the original GM film.

\section{Water contact angle determination of GM/DE-ChN nanocomposite films}

Figure. 6 showed the effects of DE-ChN addition on the water contact angle of composite films. The water contact angle of GM film was about $73^{\circ}$. DE-ChN could significantly improve the water contact angle of composite films. This was because the molecular chain of chitosan was semi-rigid and contained a large number of hydroxyl and amino groups. The hydroxy and hydroxy groups, the hydroxy groups and the amino groups or the amino groups and the amino groups were paired with each other to form a zipper-like hydrogen bond, which bind the polar groups in the film, and there were fewer polar groups on the film surface, resulting in the surface water contact angle of the GM/DE-ChN nanocomposite film increased (Liu et al. 2010). GM/20\% DE-ChN nanocomposite films had the significant maximum water contact angle of $119^{\circ}(P<0.001)$, which were increased by about $63 \%$. That may be related to the high content of hydroxyl and amino groups in the film. Compared with other samples with DE-ChN content, more hydroxyl and amino groups in the film were paired with each other, forming more zipper-like hydrogen bonds, and more polar groups of the film were bound inside, thereby reducing the polar groups on the surface of the film, resulting in a high-water contact angle of the film sample. 


\section{Cytotoxicity evaluation of GM/DE-ChN nanocomposite films}

In order to evaluate the safety of the prepared films, in vitro cytotoxicity tests were carried out for GM and GM/DE-ChN nanocomposite solutions by culturing with RAW 264.7 macrophages cells. Each sample was added to the macrophage medium at the concentration of $25-800 \mu \mathrm{g} / \mathrm{mL}$ and CK was used as a control blank (Zhou et al. 2018). The effects of different DE-ChN addition amount of GM composite solution on the toxicity of macrophages was shown in Fig. 7. On the whole, the effect of GM/DE-ChN nanocomposite solution on macrophage activity increased in a concentration-dependent manner and then decreased. Chitosan was a linear polymer of $\mathrm{N}$-acetyl-D glucosamine and deacetylglucosamine. It had certain characteristics of glycosaminoglycan and hyaluronic acid, and had certain biological activities (Tian and Ye 2012). Chitosan can promote human monocytes to produce TGF-inhibitor and platelet derived growth factor (TGF-inhibitor) (Yao et al. 2006b). In addition, chitosan treatment could also induce the expression of major histocompatibility complex (MHC) mannose receptor and other activation markers. It has been reported in the literature that polysaccharides enhance the expression of arginase, thereby enhancing the activity of arginase metabolic pathways, and stimulating the proliferation of macrophages (Bhardwaj et al. 2020).

\section{Antibacterial performance}

The sterilization property against E. coli, B. subtilis, S. aureus and S. pneumoniae of composite films was determined by the colony counting method. The bacterial suspension was inoculated in the solid medium and the numbers of total viable counts were visualized in Figure. $8 \sim 11$. The bacterial colony of $E$. coli, $B$. subtilis, $S$. aureus and $S$. pneumoniae were almost fully grown on the agar plates after the treatment of original GM film, but less observed in the presence of GM/DE-ChN nanocomposite films. The antibacterial effects of the original GM solution and the GM/DE-ChN nanocomposite solution on $E$. coli are shown in Fig. 8. As the amount of DE-ChN added in GM increased, the antibacterial effect of GM/DE-ChN nanocomposite solution on $E$. coli also increased. The inhibitory rate of $\mathrm{GM} / 40 \% \mathrm{DE}-\mathrm{ChN}$ film to $E$. coli was $7 \%$, and the inhibitory rate of $\mathrm{GM} / 60 \% \mathrm{DE}-\mathrm{ChN}$ film to $E$. coli was $33 \%$, and the antibacterial effect was significant $(P<0.01)$. The antibacterial effect of the film on B. subtilis was shown in Fig. 9. As the amount of DE-ChN added in GM increased, the antibacterial effect of DE-ChN/GM composite solution on B. subtilis also increased. GM/20\% DE-ChN, GM/40\% DE-ChN, GM/60\% DE-ChN and original DE-ChN films had an inhibitory rate of $99 \%$ against $B$. subtilis, the antibacterial effect was particularly significant $(\mathrm{P}<$ 0.001). Figure 10 showed the antibacterial effect of the film on $S$. aureus, the GM/20\% DE-ChN film had an inhibitory rate of $13 \%$ against $S$. aureus, GM/40\% DE-ChN and GM/60\% film had an inhibitory rate of $46 \%$ and $47 \%$ against $S$. aureus, and the inhibitory rate of DE-ChN film against $S$. aureus was $57 \%$, the antibacterial effect was particularly significant $(P<0.001)$. The antibacterial effect of the composite film on S. pneumoniae was shown in Fig. 11. The bacteriostatic rate of GM/20\% DE-ChN against $S$. pneumoniae was $29 \%, \mathrm{GM} / 40 \% \mathrm{DE}-\mathrm{ChN}, \mathrm{GM} / 60 \% \mathrm{DE}-\mathrm{ChN}$ and the inhibitory rates of DE-ChN against $S$. pneumoniae were significantly $88 \%, 92 \%$ and $94 \%$, respectively $(P<0.001)$. This was because the amino group in chitosan was cat ionized at $\mathrm{pH} 5.5$, then the interaction between chitosan and bacteria was 
activated (Raafat et al. 2008). The permeability of the bacterial cell membrane changes, causing internal osmotic imbalance, leading to the leakage of electrolytes such as $\mathrm{K}^{+}$and other low-molecular-weight protein components in the cell, and finally leading to the apoptosis of microorganisms (Liu et al. 2004). The different antibacterial activities of the films against gram-positive bacteria and gram-negative bacteria might be due to the different cell wall structures of the two bacteria (Jing et al. 2007). The cell wall of gram-positive bacteria was composed of polypeptidoglycan, and chitosan could easily pass through the peptidoglycan network and directly act on the cell membrane. However, the cell wall of gramnegative bacteria contained not only an inner membrane composed of peptidoglycan and lipopolysaccharide, but also an outer membrane composed of lipoproteins and phospholipids. The outer membrane of gram-negative bacteria could act as an effective external barrier for macromolecules, which might prevent the macromolecule chitosan from reaching the plasma membrane. Therefore, chitosan showed a stronger antibacterial effect on gram-positive bacteria than gram-negative bacteria.

\section{Conclusions}

The GM/DE-ChN nanocomposite films showed great antibacterial properties for the prohibition of $E$. coli, B. subtilis, $S$. aureus and S. pneumoniae. When the additional amount of DE-ChN was $60 \%$ into GM, the antibacterial rate of GM/DE-ChN nanocomposite film against E. coli, B. subtilis, S. aureus and $S$. pneumoniae reached $33 \%, 99 \%, 47 \%$ and $92 \%$. The obtained GM/DE-ChN nanocomposite films had improved tensile strength (107 MPa), which was $343 \%$ higher than the original GM film. The GM/DE-ChN nanocomposite films had excellent hydrophobicity of $107^{\circ}$, which was $147 \%$ higher than the original GM film. Moreover, the GM/DE-ChN nanocomposite film showed no toxicity to macrophage cells. The above conclusions indicated that the biocompatible DE-ChN had significant antibacterial properties against common bacteria. The physical and chemical properties of GM films were improved. Therefore, combining $\mathrm{DE}-\mathrm{ChN}$ with renewable and sustainable packaging materials to prepare packaging materials with antibacterial properties will provide a new method for food packaging without harmful additives.

\section{Declarations}

\section{Acknowledgements}

This work was supported by the National Key R\&D Program of China (2016YFD0600803) and the Priority Academic Program Development of Jiangsu Higher Education Institution (PAPD).

\section{Author contribution}

Wanying Liu: Conceptualization, Methodology, Formal analysis, Writing-Original Draft, Writing-Review \& Editing.

Ling Zhe: Visualization 
Caoxing Huang: Resources

Chenhuan Lai: Data curation

Qiang Yong: Supervision, Project administration; Funding acquisition

\section{Compliance with ethical standards}

\section{Conflict of interest}

The authors declare no competing financial interest.

\section{References}

1. Antoniou J, Liu F, Majeed H, et al (2014) Physicochemical and thermomechanical characterization of tara gum edible films: Effect of polyols as plasticizers. Carbohydr Polym 111:359-365. https://doi.org/10.1016/j.carbpol.2014.04.005

2. Bhardwaj S, Bhardwaj NK, Negi YS (2020) Effect of degree of deacetylation of chitosan on its performance as surface application chemical for paper-based packaging. Cellulose 27:5337-5352. https://doi.org/10.1007/s10570-020-03134-5

3. Chien RC, Yen MT, Mau JL (2016) Antimicrobial and antitumor activities of chitosan from shiitake stipes, compared to commercial chitosan from crab shells. Carbohydr Polym 138:138-259. https://doi.org/10.1016/j.carbpol.2015.11.061

4. Darbasi M, Askari G, Kiani H, Khodaiyan F (2017) Development of chitosan based extended-release antioxidant films by control of fabrication variables. Int J Biol Macromol 104:303-310. https://doi.org/10.1016/j.ijbiomac.2017.06.055

5. Fan Y, Saito T, Isogai A (2010) Individual chitin nano-whiskers prepared from partially deacetylated achitin by fibril surface cationization. Carbohydr Polym 79:1046-1051. https://doi.org/10.1016/j.carbpol.2009.10.044

6. Galus S, Kadzińska J (2015) Food applications of emulsion-based edible films and coatings. Trends Food Sci. Technol. 273-283

7. Gennadios A, Rhim JW, Handa A, et al (1998) Ultraviolet radiation affects physical and molecular properties of soy protein films. J Food Sci 63:225-228. https://doi.org/10.1111/j.13652621.1998.tb15714.x

8. Gutiérrez TJ, Morales NJ, Pérez E, et al (2015) Physico-chemical properties of edible films derived from native and phosphated cush-cush yam and cassava starches. Food Packag Shelf Life 3:1-8. https://doi.org/10.1016/j.fpsl.2014.09.002

9. Jing YJ, Hao YJ, Qu H, et al (2007) Studies on the antibacterial activities and mechanisms of chitosan obtained from cuticles of housefly larvae. Acta Biol Hung 58:75-86. 
https://doi.org/10.1556/ABiol.57.2007.1.7

10. Jóźwiak T, Filipkowska U, Szymczyk P, et al (2017) Effect of ionic and covalent crosslinking agents on properties of chitosan beads and sorption effectiveness of Reactive Black 5 dye. React Funct Polym 114:58-74. https://doi.org/10.1016/j.reactfunctpolym.2017.03.007

11. Khan RA, Salmieri S, Dussault D, et al (2012) Preparation and Thermo-Mechanical Characterization of Chitosan Loaded Methylcellulose-Based Biodegradable Films: Effects of Gamma Radiation. J Polym Environ 20:43-52. https://doi.org/10.1007/s10924-011-0336-y

12. Kong M, Chen XG, Xing K, Park HJ (2010) Antimicrobial properties of chitosan and mode of action: $A$ state of the art review. Int. J. Food Microbiol. 51-63

13. Lawrie G, Keen I, Drew B, et al (2007) Interactions between alginate and chitosan biopolymers characterized using FTIR and XPS. Biomacromolecules 8:2533-2541. https://doi.org/10.1021/bm070014y

14. Lee KY, Shim J, Lee HG (2004) Mechanical properties of gellan and gelatin composite films. Carbohydr Polym 56:251-254. https://doi.org/10.1016/j.carbpol.2003.04.001

15. Li H, Gao X, Wang Y, et al (2013) Comparison of chitosan/starch composite film properties before and after cross-linking. Int J Biol Macromol 52:275-279. https://doi.org/10.1016/j.jibiomac.2012.10.016

16. Li X, Li HC, You TT, et al (2019) Fabrication of regenerated cellulose membranes with high tensile strength and antibacterial property via surface amination. Ind Crops Prod 140:111603. https://doi.org/10.1016/j.indcrop.2019.111603

17. Liu H, Du Y, Wang X, Sun L (2004) Chitosan kills bacteria through cell membrane damage. Int J Food Microbiol 95:147-155. https://doi.org/10.1016/j.jijoodmicro.2004.01.022

18. Liu L, Wang R, Yu J, et al (2016) Robust Self-Standing Chitin Nanofiber/Nanowhisker Hydrogels with Designed Surface Charges and Ultralow Mass Content via Gas Phase Coagulation. Biomacromolecules 17:3773-3781. https://doi.org/10.1021/acs.biomac.6b01278

19. Liu XF, Wang XD, Na P, et al (2010) Evolutionary mechanism of b-oriented TS-1 film on porous aAl203 supported chitosan surface in hydrothermal reactions. Chinese Sci Bull 55:3131-3137. https://doi.org/10.1007/s11434-010-4055-x

20. Martins JT, Cerqueira MA, Vicente AA (2012) Influence of a-tocopherol on physicochemical properties of chitosan-based films. Food Hydrocoll 27:220-227. https://doi.org/10.1016/j.foodhyd.2011.06.011

21. Mollah MZI, Akter N, Quader FB, et al (2016) Biodegradable Colour Polymeric Film (Starch-Chitosan) Development: Characterization for Packaging Materials. Open J Org Polym Mater 1:. https://doi.org/10.4236/ojopm.2016.61002

22. No HK, Young Park N, Ho Lee S, Meyers SP (2002) Antibacterial activity of chitosans and chitosan oligomers with different molecular weights. Int J Food Microbiol 74:65-72. https://doi.org/10.1016/S0168-1605(01)00717-6 
23. Pang J, Wu M, Zhang Q, et al (2015) Comparison of physical properties of regenerated cellulose films fabricated with different cellulose feedstocks in ionic liquid. Carbohydr Polym 121:71-78. https://doi.org/10.1016/j.carbpol.2014.11.067

24. Park S II, Stan SD, Daeschel MA, Zhao Y (2005) Antifungal coatings on fresh strawberries (Fragaria $x$ ananassa) to control mold growth during cold storage. J Food Sci 70:202-207. https://doi.org/10.1111/j.1365-2621.2005.tb07189.x

25. Pinotti A, García MA, Martino MN, Zaritzky NE (2007) Study on microstructure and physical properties of composite films based on chitosan and methylcellulose. Food Hydrocoll 21:66-72. https://doi.org/10.1016/j.foodhyd.2006.02.001

26. Raafat D, Von Bargen K, Haas A, Sahl HG (2008) Insights into the mode of action of chitosan as an antibacterial compound. Appl Environ Microbiol 74:3764-3773. https://doi.org/10.1128/AEM.00453-08

27. Sudarshan NR, Hoover DG, Knorr D (1992) Antibacterial Action of Chitosan. Food Biotechnol 6:257272. https://doi.org/10.1080/08905439209549838

28. Tian S, Ye Z (2012) [The effect of physical properties of chitosan on cell activity and on its mechanics property]. Sheng Wu Yi Xue Gong Cheng Xue Za Zhi

29. Verlee A, Mincke S, Stevens C V. (2017) Recent developments in antibacterial and antifungal chitosan and its derivatives. Carbohydr. Polym. 268-283

30. Wang Y, Shao Z, Wang F, et al (2017) Multifunctional hybrid films prepared by aqueous stabilization of graphene sheets viaing cellulose nanofibers and exfoliated montmorillonite system. Eur Polym J 86:85-93. https://doi.org/10.1016/j.eurpolymj.2016.08.036

31. William Kemp M (2002) Organic spectroscopy. J. Chem. Educ.

32. Wu C, Peng S, Wen C, et al (2012) Structural characterization and properties of konjac glucomannan/curdlan blend films. Carbohydr Polym 89:497-503. https://doi.org/10.1016/j.carbpol.2012.03.034

33. Xiao Q, Tong Q, Lim LT (2012) Pullulan-sodium alginate based edible films: Rheological properties of film forming solutions. Carbohydr Polym 87:1689-1695. https://doi.org/10.1016/j.carbpol.2011.09.077

34. Xu J, Liu L, Yu J, et al (2019) DDA (degree of deacetylation) and pH-dependent antibacterial properties of chitin nanofibers against Escherichia coli. Cellulose 26:2279-2290. https://doi.org/10.1007/s10570-019-02287-2

35. Yao S, Zhao Z, Zhang W, Wang H (2006a) Preparation of Fe304 film by in-situ oxidative hydrolysis on chitosan. J Mater Sci Technol 22:329-332

36. Yao Z, Wu H, Han B, Liu W (2006b) The effect of the degree of deacetylation of chitosan on the biocompatibility of chitosan membrane with corneal stromal cells. Sheng Wu Yi Xue Gong Cheng Xue Za Zhi 4:

37. Ye W, Liu L, Yu J, et al (2018) Hypolipidemic activities of partially deacetylated a-chitin nanofibers/nanowhiskers in mice. Food Nutr Res 62:1295-1303. 
https://doi.org/10.29219/fnr.v62.1295

38. Zheng LY, Zhu JF (2003) Study on antimicrobial activity of chitosan with different molecular weights. Carbohydr Polym 54:527-530. https://doi.org/10.1016/j.carbpol.2003.07.009

39. Zhou M, Yang L, Yang S, et al (2018) Isolation, characterization and in vitro anticancer activity of an aqueous galactomannan from the seed of Sesbania cannabina. Int J Biol Macromol 113:12411247. https://doi.org/10.1016/j.ijbiomac.2018.03.067

\section{Figures}

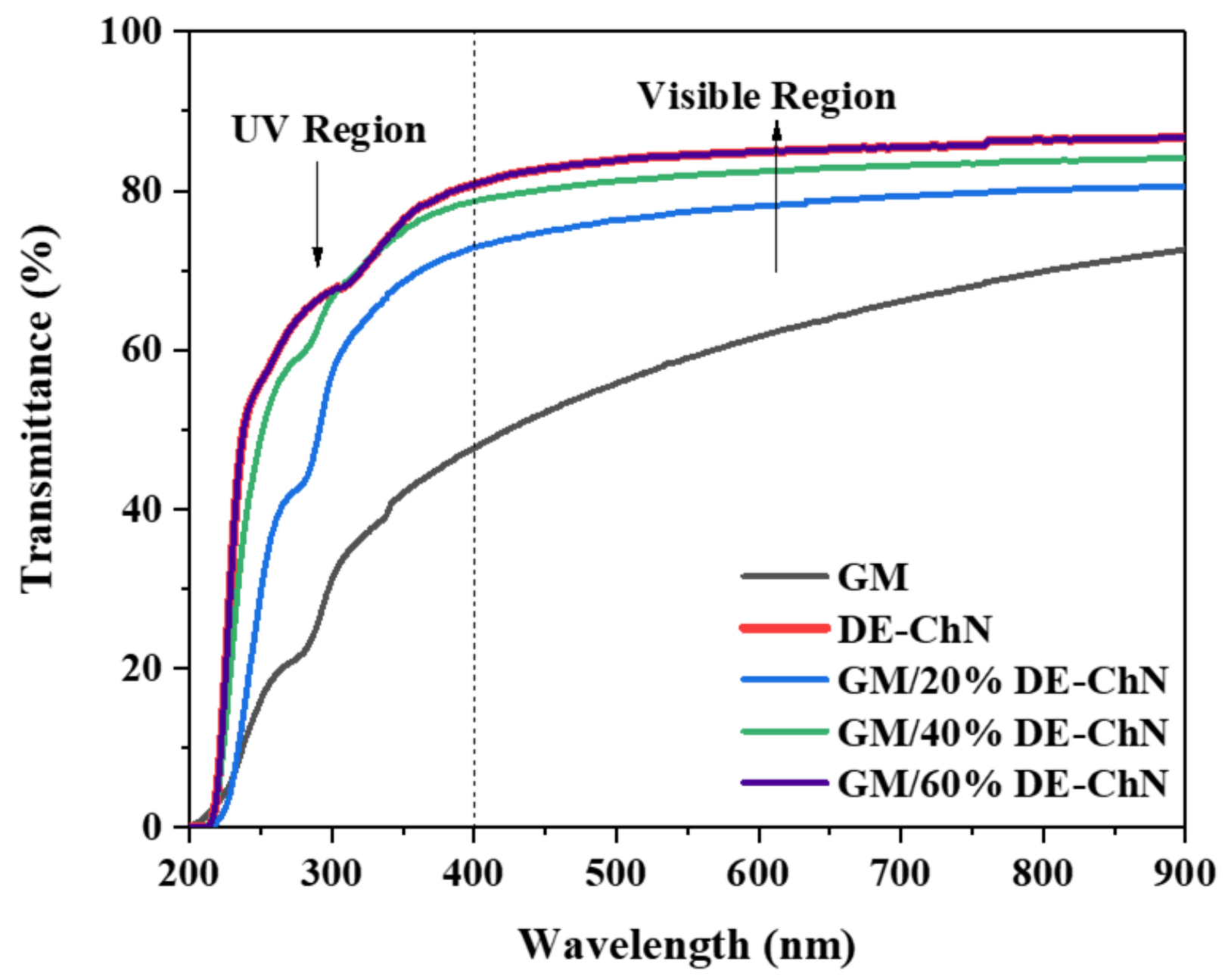

Figure 1

UV transmittance of GM/DE-ChN nanocomposite films 


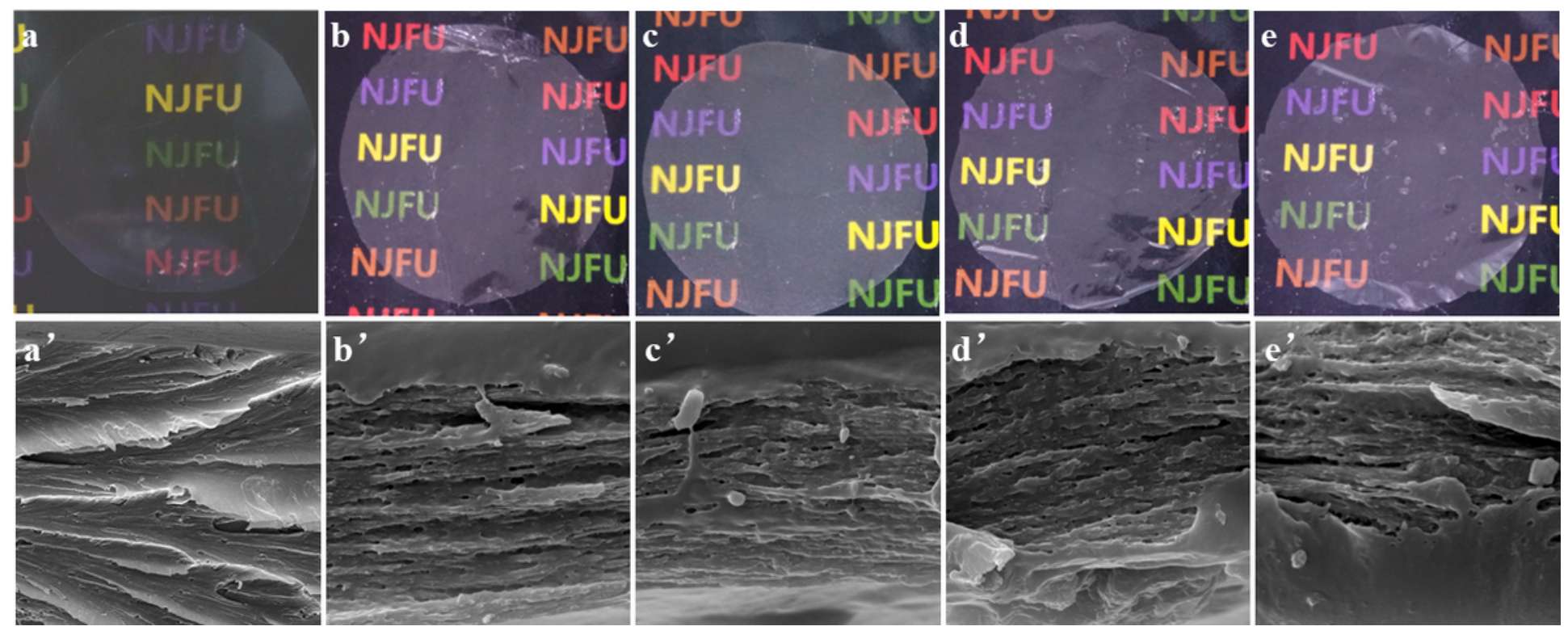

Figure 2

Digital (a e) and SEM (a' e') images of the cross-section of GM/DE-ChN nanocomposite films: (a) Original GM film; (b) GM/20\%DE-ChN film; (c) GM/40\%DE-ChN film; (d) GM/60\%DE-ChN film; (e) Original DE-ChN film 


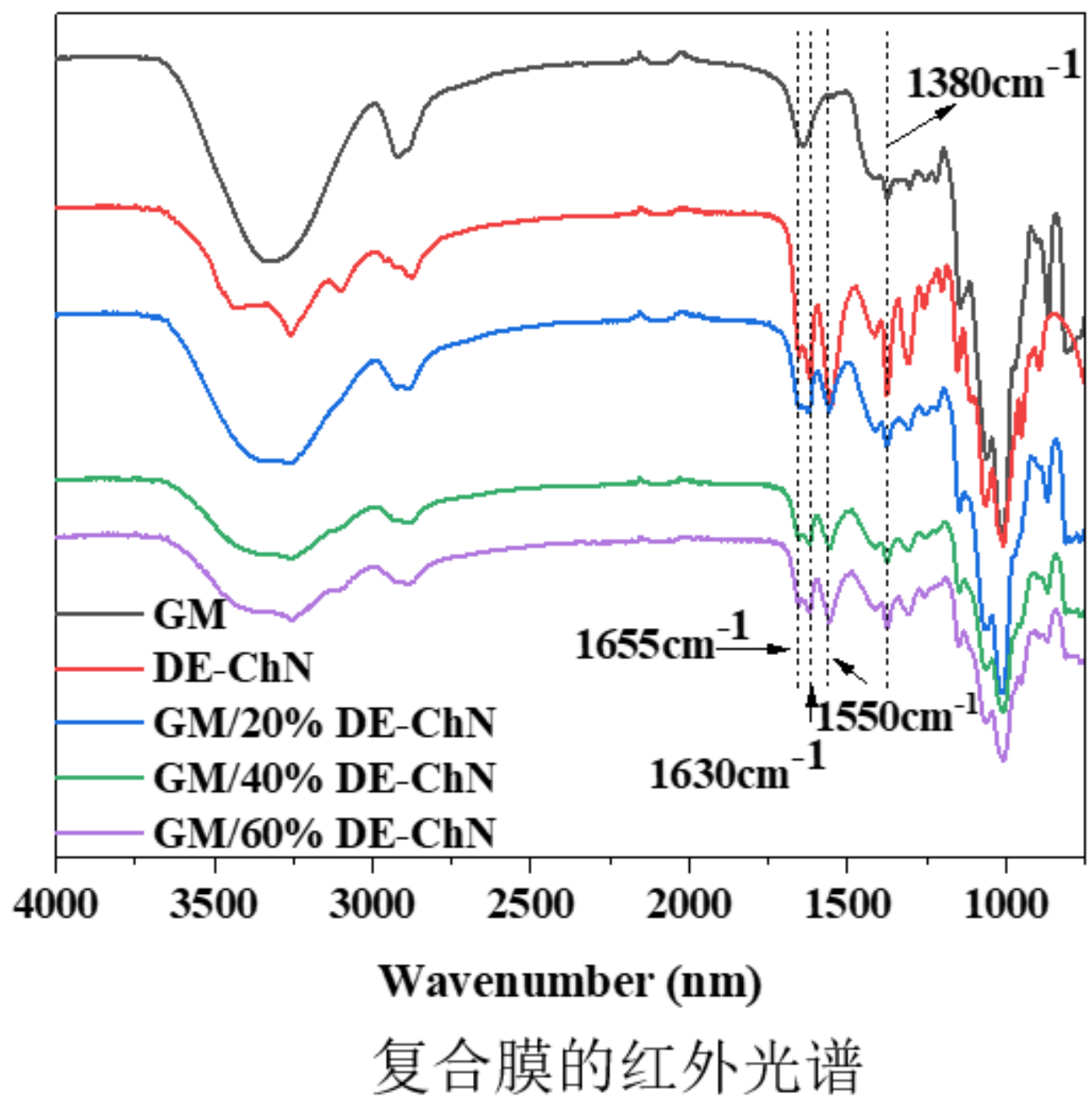

Figure 3

FT-IR spectra of GM/DE-ChN nanocomposite films

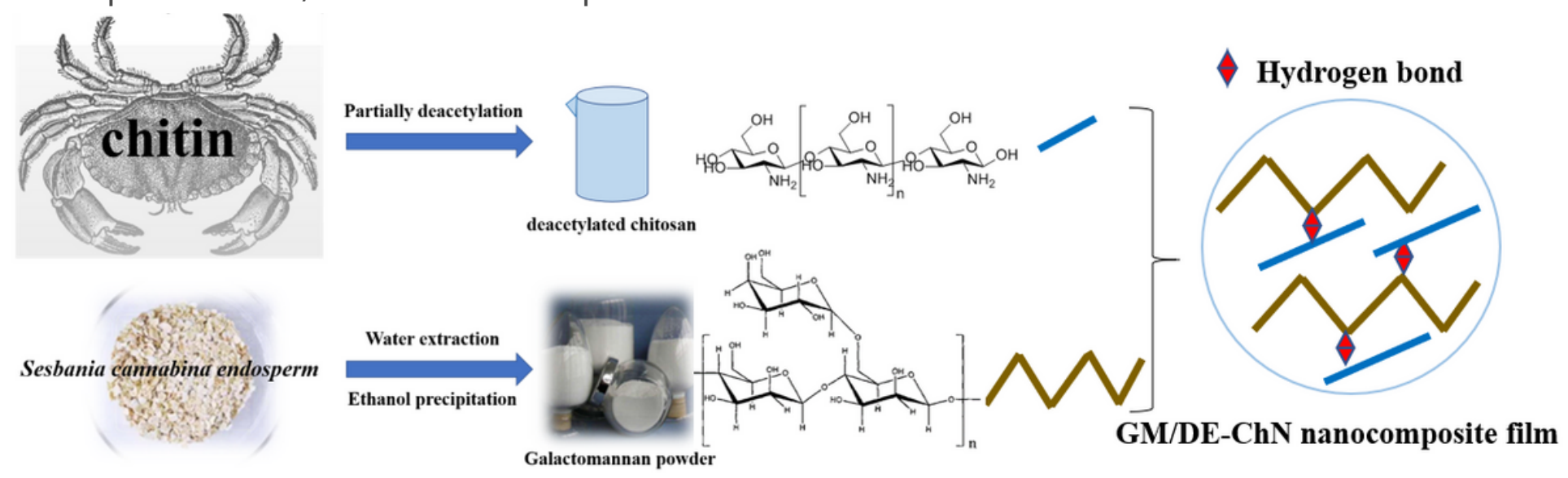

Figure 4 
The hypothetical interaction mechanism of DE-ChN and GM in nanocomposite films.
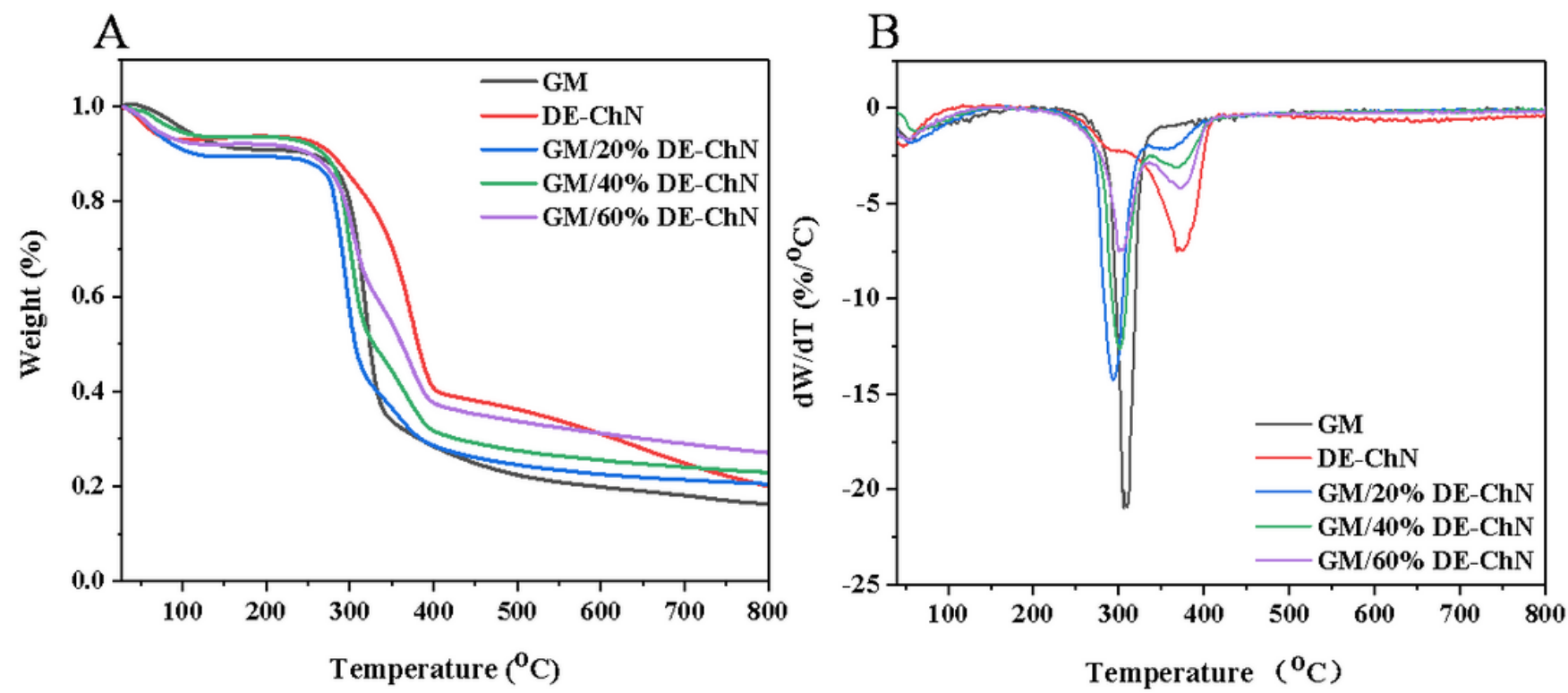

Figure 5

TGA (A) and DTG (B) analysis for GM/DE-ChN nanocomposite films.

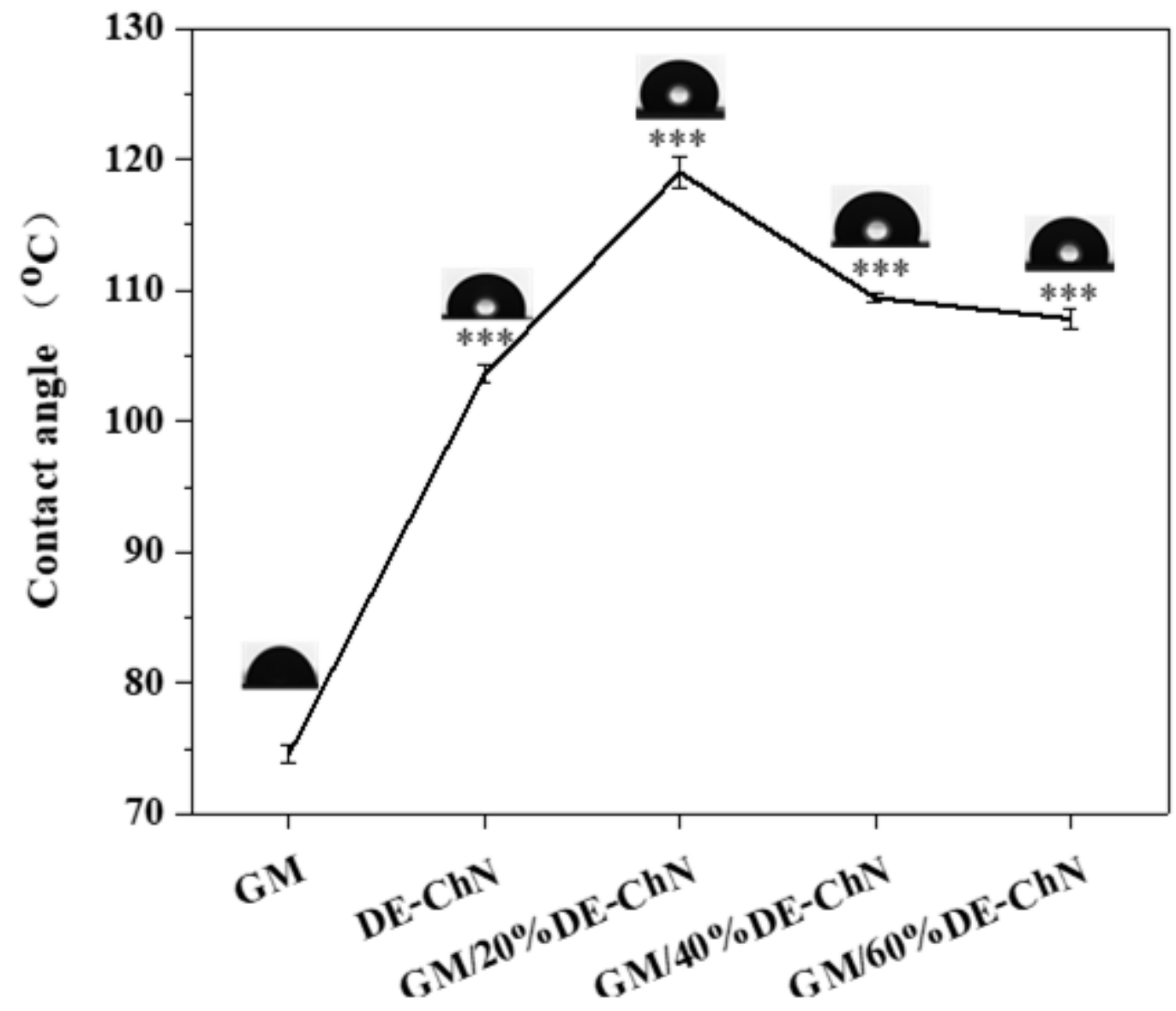

Figure 6 
The water contact angle of GM/DE-ChN nanocomposite films $(P<0.05 *, P<0.01 * \star, P<0.001 * \star *)$

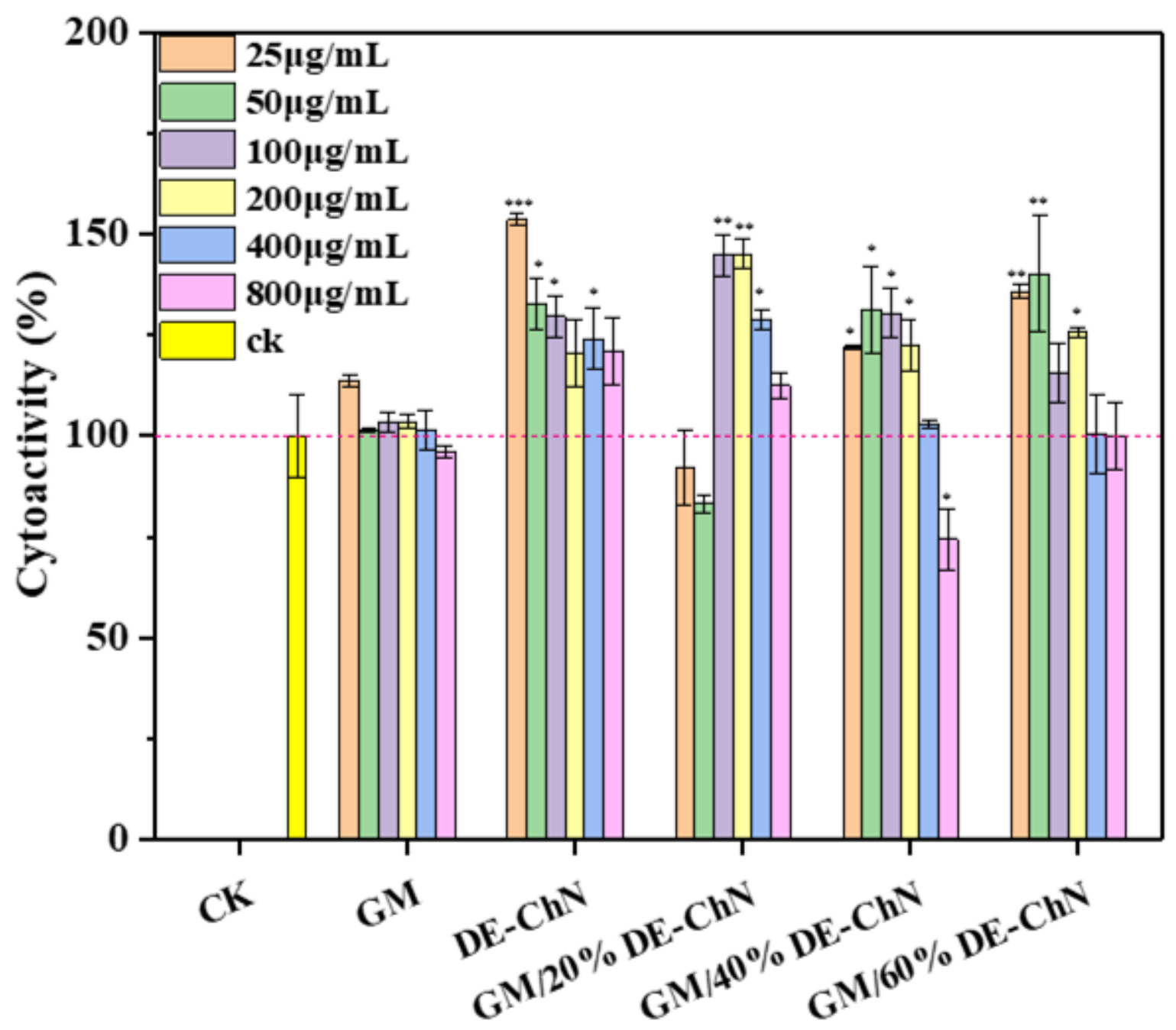

Figure 7

Effects of the GM and GM/DE-ChN nanocomposite films on macrophage activity $(P<0.05 *, P<0.01$ **, $\mathrm{P}<0.001 * \star \star)$ 

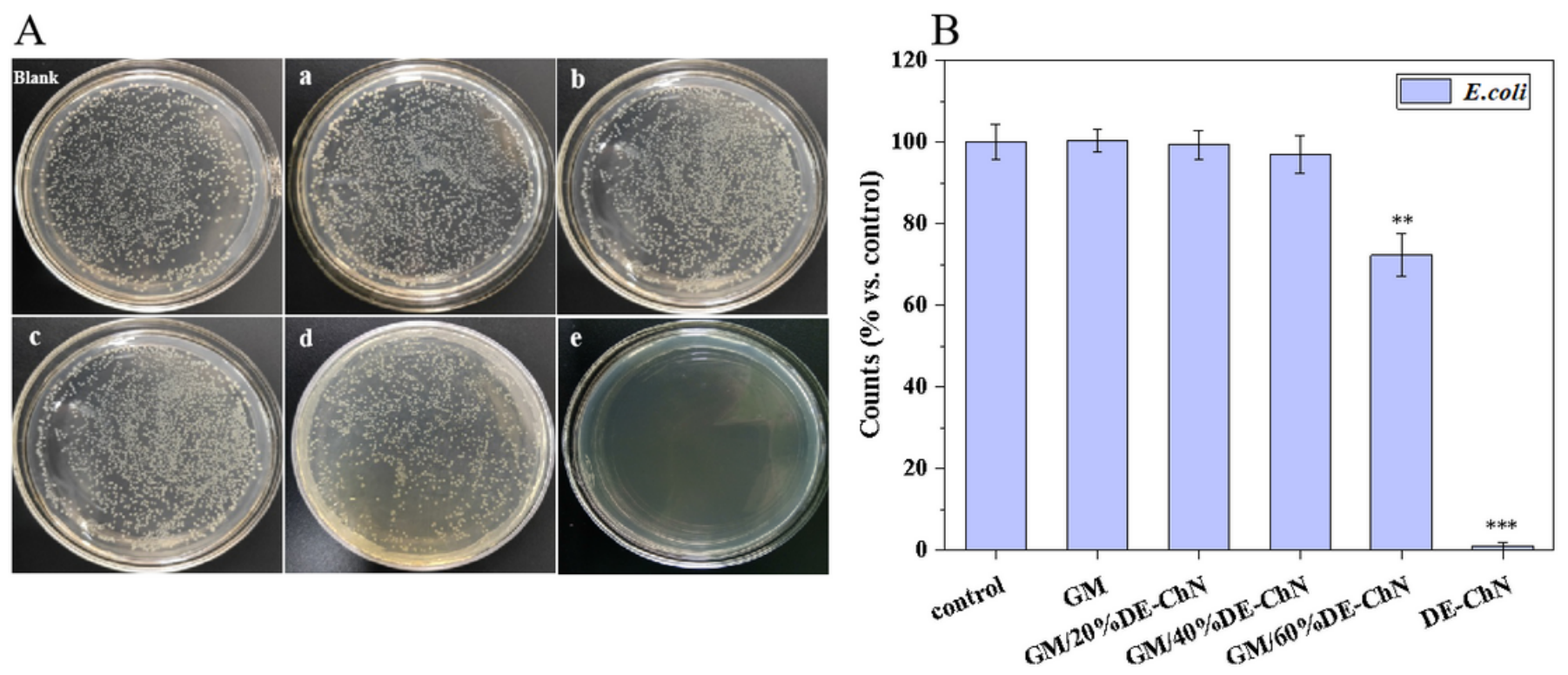

Figure 8

Antibacterial effect of treating E. coli with nanocomposite films (Blank control group, a GM film, $b$ GM/20\%DE-ChN film, c GM/40\%DE-ChN film, d GM/60\%DE-ChN film, e DE-ChN film) $(P<0.05 *, P<0.01$ **, $\mathrm{P}<0.001 * * *)$
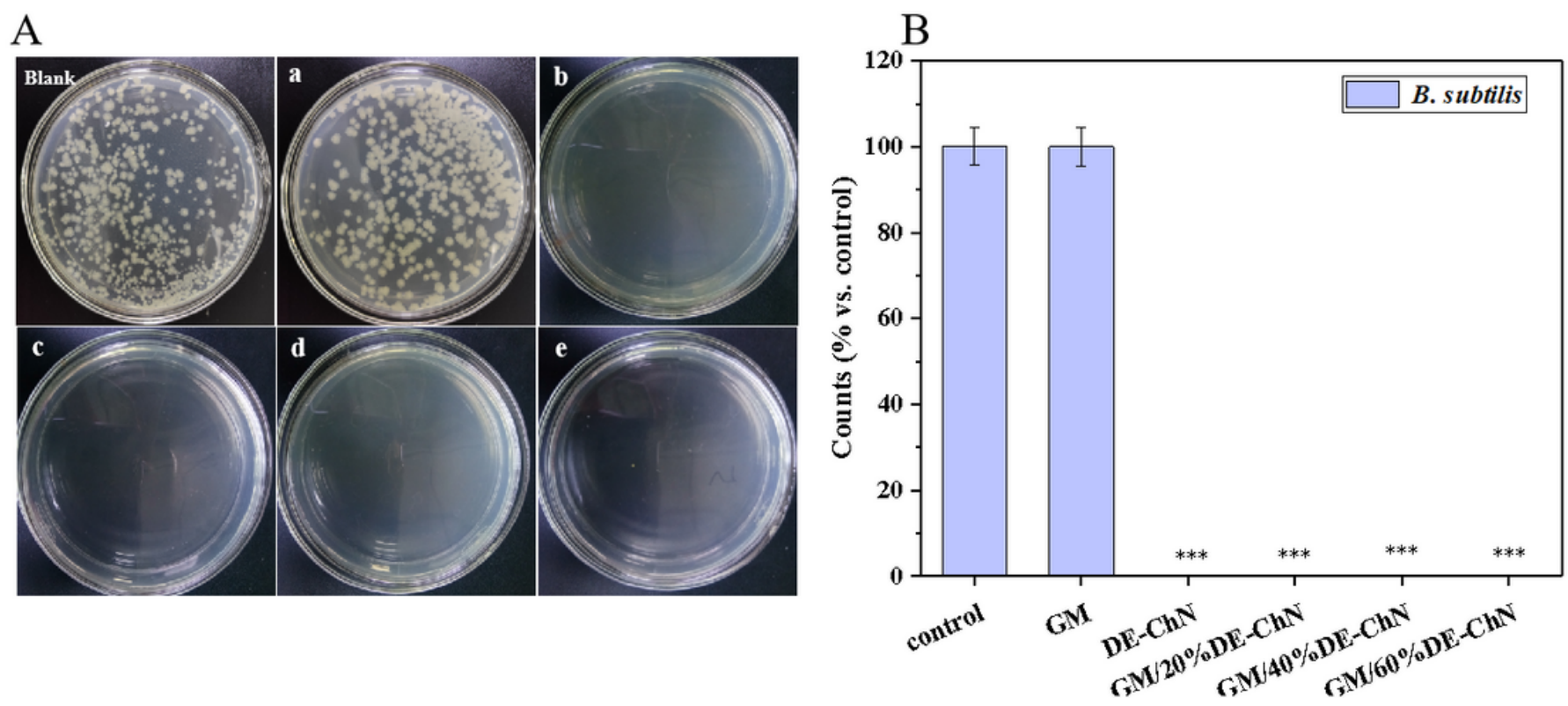

Figure 9

Antibacterial effect of treating B. subtilis with nanocomposite films (Blank control group, a GM film, $b$ GM/20\%DE-ChN film, c GM/40\%DE-ChN film, d GM/60\%DE-ChN film, e DE-ChN film) $(P<0.05 *, P<0.01$ **, $\mathrm{P}<0.001 \star \star \star)$ 
A
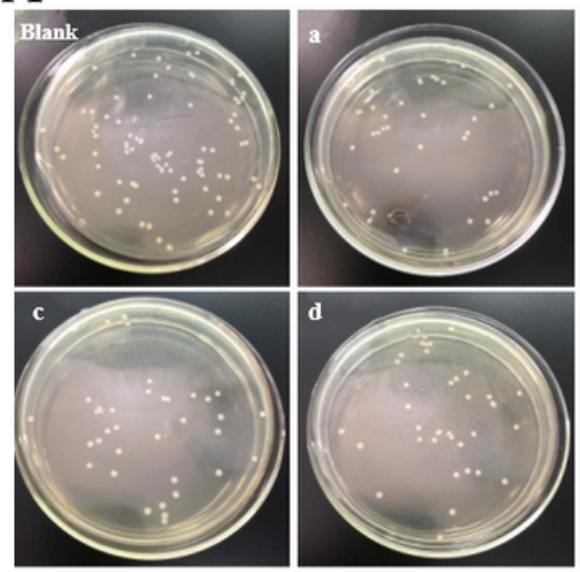
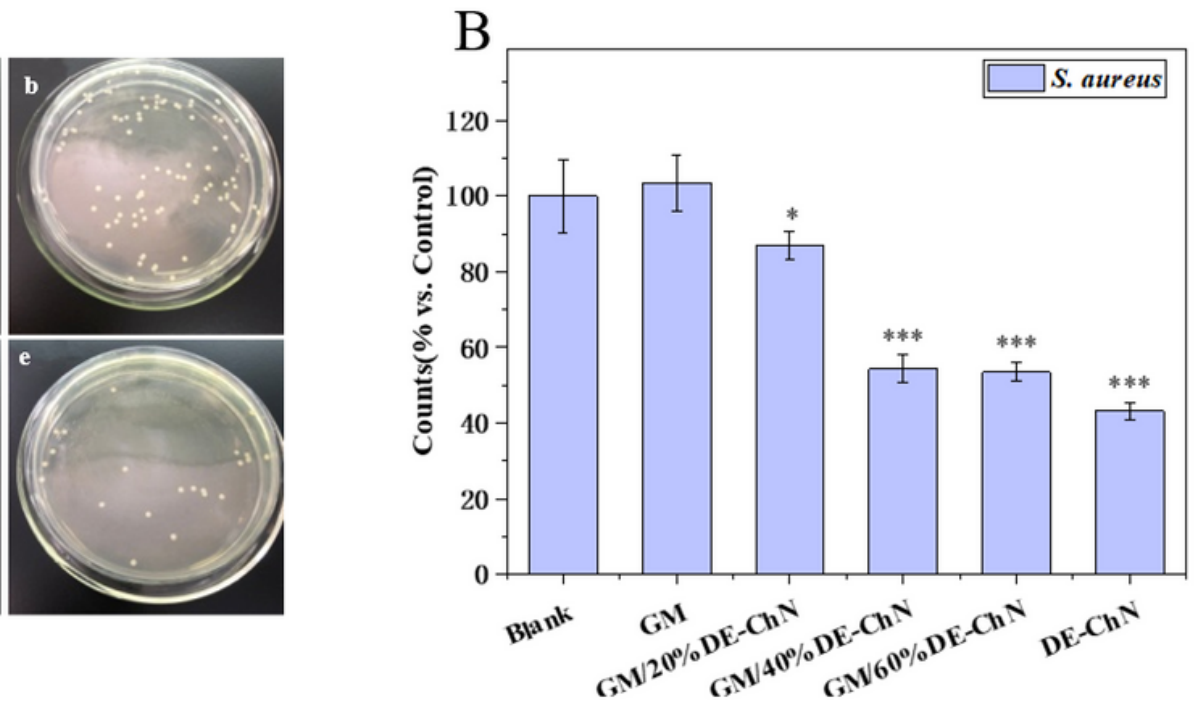

Figure 10

Antibacterial effect of treating S. aureus with nanocomposite films (Blank control group, a GM film, b GM/20\%DE-ChN film, c GM/40\%DE-ChN film, d GM/60\%DE-ChN film, e DE-ChN film) $(P<0.05 *, P<0.01$ **, $\mathrm{P}<0.001 \star \star \star)$
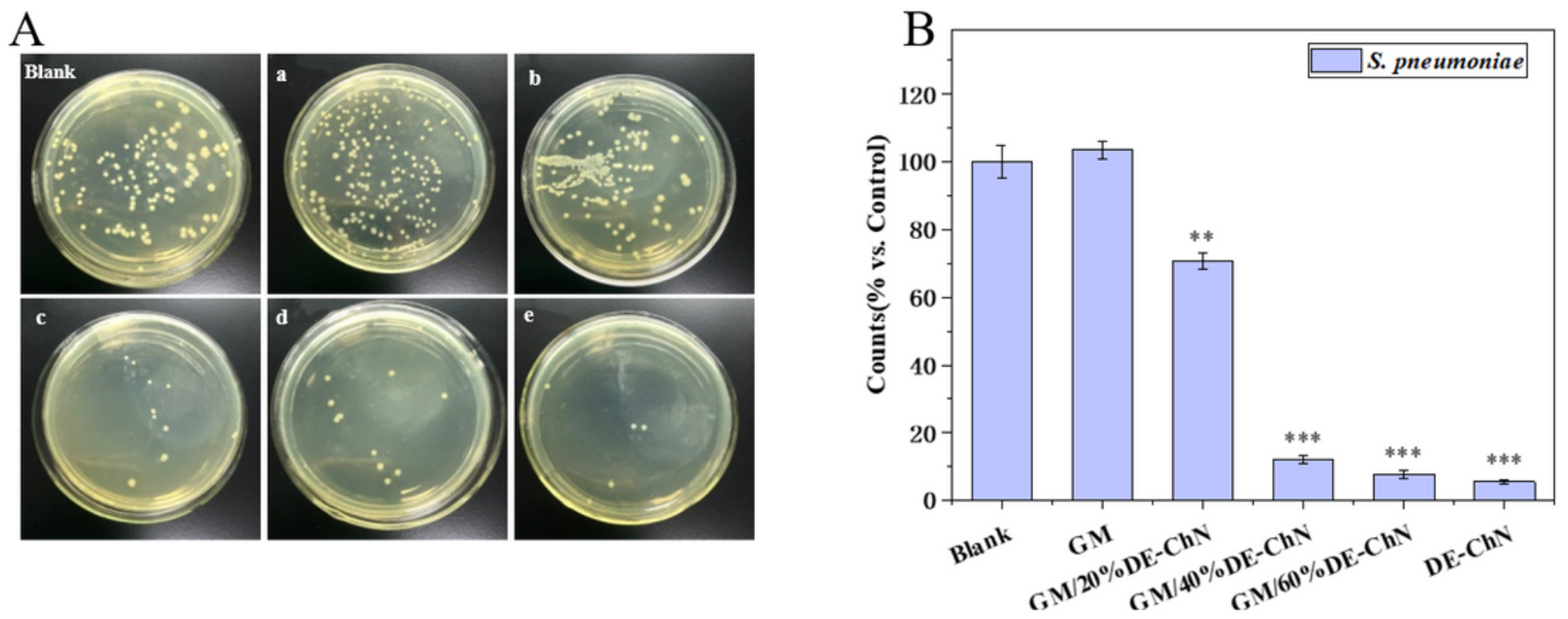

\section{Figure 11}

Antibacterial effect of treating S. pneumoniae with nanocomposite films (Blank control group, a GM film, b GM/20\%DE-ChN film, c GM/40\%DE-ChN film, d GM/60\%DE-ChN film, e DE-ChN film) $(P<0.05$ *, $P<0.01$ $\star \star, P<0.001 * \star *)$ 